\title{
Changes in ventilation and its components in normal subjects during sleep
}

\author{
JR STRADLING, GA CHADWICK, AJ FREW \\ From the Osler Chest Unit, Churchill Hospital, Oxford
}

ABSTRACT Non-invasive measurements were made of ventilation, its derivatives, the contributions of abdomen and ribcage and arterial oxygen saturation in six healthy normal men whilst awake and during sleep. Minute ventilation fell significantly during slow wave (SW) sleep and rapid eye movement $(\mathrm{REM})$ sleep $\left(\right.$ awake $=6.31 \mathrm{~min}^{-1}, \mathrm{SW}$ sleep $=5.71 \mathrm{~min}^{-1}$, $\mathrm{REM}$ sleep $=$ $\left.5.41 \mathrm{~min}^{-1} ; \mathrm{p}<0.04\right)$. Mean inspiratory flow also fell significantly but timing was unchanged. The abdominal (diaphragmatic) contribution to ventilation fell very significantly during SW sleep but returned to awake levels during REM sleep (awake 54\%, SW sleep 38\%, REM sleep 56\%; p < $0 \cdot 007)$. There were also significant falls in arterial oxygen saturation during SW and REM sleep (awake 97.3\%, SW sleep 96.5\%, REM sleep 96.2\%; p < 0.002). These falls represent reductions in arterial oxygen tension similar to those seen in patients with chronic airways obstruction and can be accounted for entirely by the associated reduction in ventilation.

Interest is growing in the relationship between abnormalities of nocturnal breathing and the development of daytime symptoms. This relationship is most clearly seen in the obstructive sleep apnoea syndrome. ${ }^{\prime}$ It is, however, known that patients with hypoxic lung disease become even more hypoxaemic during sleep. ${ }^{23}$ By analogy with obstructive sleep apnoea, it has been suggested that this extra hypoxaemia may hasten the development of cor pulmonale. ${ }^{45}$ Although the extra hypoxaemia was initially thought to occur in those with abnormal nocturnal breathing, later studies suggested that the drop in oxygen tension was similar throughout a large and varied group of patients with chronic airways obstruction and that the severity of the drops in oxygen saturation simply reflected their position on the oxyhaemoglobin dissociation curve. ${ }^{6}$ Thus the question arose whether patients with nocturnal hypoxaemia and normal subjects show similar falls in oxygen tension and in alveolar ventilation.

Patients with bilateral diaphragm paralysis suffer severe nocturnal hypoxaemia during rapid eye movement (REM) sleep. ${ }^{7}$ The mechanism proposed is based on limited evidence that during REM sleep, breathing in normal subjects is mainly diaphragma-

Address for reprint requests: Dr JR Stradling, Churchill Hospital, Oxford.

Accepted 3 December 1984 tic owing to physiological inhibition of the intercostal muscles. ${ }^{89}$ Consequently a patient depending entirely on his intercostal muscles would hypoventilate considerably during REM sleep. Patients with chronic airways obstruction and hyperinflation have diaphragms that are flat and at a mechanical disadvantage, leading to a smaller contribution by the diaphragm to their tidal volumes than in normal subjects. ${ }^{10}$ These patients may behave in a qualitatively similar way to patients with bilateral diaphragm paralysis, in that they may be more vulnerable to the inhibition of intercostal muscles during REM sleep and thus hypoventilate more than normal subjects. It is therefore important to know the extent to which the compartmental contribution to ventilation changes normally with sleep.

Previous studies of ventilation during sleep have had various limitations, the most important being the use of mouthpiece or masks. These are known to produce changes in the pattern of breathing, ${ }^{11-13}$ but their different effects on ventilation during wakefulness and sleep are not known. Recent evidence suggests that a mask enclosing both nose and mouth has little effect on respiratory rate during sleep, but that the sleep is more disturbed. ${ }^{14}$ The best available study in normal subjects used a tight fitting mask and gave no information on the contributions from ribcage and diaphragm. ${ }^{15}$ That study was performed at altitude of $1600 \mathrm{~m}$, so a degree of hypoxaemia was present that may have increased ventilation 
more during the wakefulness than during asleep, since hypoxic sensitivity is diminished during sleep. ${ }^{16} 17$ The only study using body surface motion to derive ventilation in normal subjects, ${ }^{18}$ without disturbing the face, was performed before it had become clear how seriously changes in posture affect the accuracy of the calibration with this technique. ${ }^{1920}$ Thus the values for changes in ventilation and the relative ribcage and abdominal contributions found in this study may have been incorrect owing to errors in calibration.

We have studied non-invasively the changes in ventilation and its derivatives, in the relative contributions of the ribcage and abdomen, and in arterial oxygen saturation that occur during sleep in normal subjects. We believe that the techniques we have used to measure ventilation and the relative contributions of ribcage and abdomen to tidal volume are more appropriate than those used in previous studies.

\section{Methods}

\section{SUBJECTS}

Six healthy men aged 18-32 years were studied. None were smokers and none had had a recent respiratory tract infection. One had experienced mild asthma when younger but not in the previous year and all had normal spirometric indices. None had taken any medication or received stimulant drinks for four hours before the study. Obesity indices (weight $(\mathrm{kg}) /$ height $(\mathrm{m})^{2}$ ) ranged from 23 to 29 , the normal range being 23-26. None had any complaints related to sleeping. The subjects were fully aware of the nature and purpose of the study. Four of the six subjects had only five hours sleep the night before the study; the other two had had normal nights.

\section{TECHNIQUES}

The subjects were studied recumbent in a tipping chair (Buxton type) with the angle between the seat and the back opened out to $120^{\circ}$ (fig 1). This effectively prevented any change in posture that could have altered the calibration of the respiratory inductance plethysmograph: in particular, the spinal angle was fixed. This chair, although very comfortable, disturbed sleep to some extent because it limited movement.

Respiratory inductance plethysmography was used to measure ventilation on the basis of, ${ }^{21}$ changes in self inductance of wire "zigzags" on belts around the chest and abdomen. The belts were individually prepared from stretchy sticking plaster and firmly stuck to the skin to prevent slippage. By the application of appropriate constants (volume

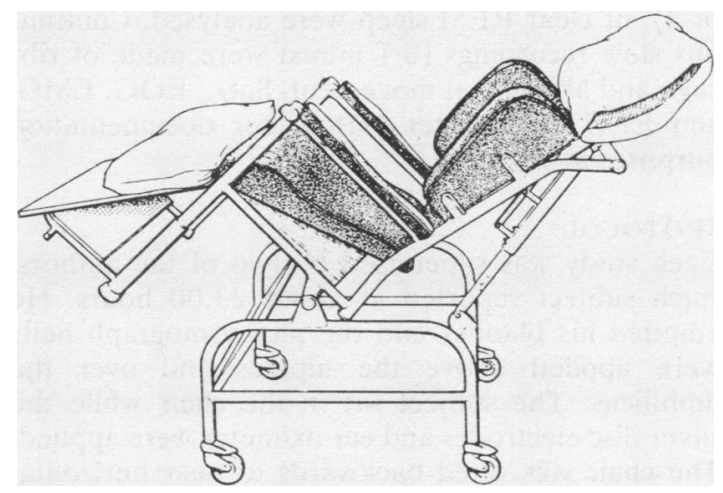

Fig 1 Modified "Buxton" tipping chair for maintenance of a fixed posture throughout the studies.

motion (V-M) coefficients) the electrical signals are calibrated to represent the volume of air displaced in the lungs. If the respiratory pump behaves with two degrees of freedom then these two belts will correctly represent all the air going in and out of the lungs. The RIP was calibrated by multiple linear regression, a microcomputer being used..$^{22}$ The accuracy of the V-M coefficients was tested by comparing RIP tidal volume measurements obtained by respiratory inductance plethysmography with those obtained by spirometry. Some of the comparisons were done during normal breathing and some with deliberate changes in relative ribcage and abdominal contributions. ${ }^{23}$ This procedure was repeated at the end of the experiment with a range of ribcage and abdominal contributions covering the range seen during the study and any implied change in V-M coefficients was calculated. If the drift was more than $5 \%$ then the data were recalculated with the new V-M coefficients since the data actually analysed were always nearer the end of the study than the beginning.

Arterial oxygen saturation $\left(\mathrm{SaO}_{2}\right)$ was measured with an ear lobe oximeter (Biox). Although at high saturations this instrument has an error of $\pm 2 \%,{ }^{24}$ the changes in $\mathrm{SaO}_{2}$ in an individual are more accurately represented. ${ }^{25}$

Continuous monitoring of electroencephalogram (EEG), submental electromyogram (EMG), and electro-oculogram (EOG) was performed to stage the sleep and define wakefulness according to standard criteria. ${ }^{26}$ This staging was done at the time of the study from the signals displayed on a large monitor or from a polygraph recorder (Beckmann) at $25 \mathrm{~mm} / \mathrm{s}$. Changes from one state to another were not sudden and only data from periods of at least 10 minutes' clear wakefulness, clear SW sleep (stage 3 
or 4), or clear REM sleep were analysed. Continuous slow recordings $(0 \cdot 1 \mathrm{~mm} / \mathrm{s})$ were made of ribcage and abdominal movement, $\mathrm{SaO}_{2}$, EOG, EMG, and EEG, with faster periods for documentation purposes at $25 \mathrm{~mm} / \mathrm{s}$.

\section{PROTOCOL}

Each study was supervised by two of the authors. Each subject reported at about 23.00 hours. He emptied his bladder and the plethysmograph belts were applied above the nipples and over the umbilicus. The subject sat in the chair while the silver disc electrodes and ear oximeter were applied. The chair was tilted backwards to near horizontal and the subject made comfortable with pillows under the head and legs. Calibration and testing of the respiratory inductance plethysmograph was then performed. The lights were turned off at about 23.45 hours. A sensitive intercom allowed any periods of snoring to be detected and these were not analysed. Ventilation was monitored breath by breath with the aid of the microcomputer ${ }^{23}$ and the mean values were printed out each minutes together with the $\mathrm{SaO}_{2}$ at that time; a signal was also passed to the polygraph for synchronisation. Sleep stages 1 or 2 with periodic arousals were always seen initially, followed by SW sleep stages 3 or 4. REM sleep usually occurred within 90 minutes and lasted about 30 minutes. If this was immediately followed by SW sleep stages 3 or 4 then a further 15 minutes was recorded, the subjects was woken, and 15 minutes of "awake" data were recorded, followed by calibration tests. If the subject awoke spontaneously after the REM sleep period then the 15 minute awake period was immediately recorded, followed by calibration tests. In this way consecutive periods of REM and SW sleep and wakefulness (or SW and REM sleep and wakefulness) were available for analysis within a period of less than 80 minutes. This further minimised any possible effects of changes in calibration of the respiratory inductance plethysmograph.

DATA

Averages of minute ventilation, frequency, tidal volume, mean inspiratory flow (VT/TI), fractional inspiratory time (TI/TTOT), abdominal contribution (as a volumetric fraction determined after application of V-M coefficients) were calculated each minute by the computer. A minimum of 10 minutes' data for each stage were further averaged by hand and the standard deviation was calculated. This allowed the minute to minute coefficient of variation ( $\mathrm{SD} /$ mean) for each variable during each state to be calculated. Changes were tested for statistical significance by means of paired Student' $\boldsymbol{t}$ tests: awake versus SW sleep, awake versus REM sleep, and SW versus REM sleep.

Alveolar ventilation was estimated approximately by assuming an anatomical dead space of $150 \mathrm{ml}$. A multicompartment computer simulation of gas exchange $^{27}$ was used to assess whether the changes observed in $\mathrm{SaO}_{2}$ could be explained on the basis of changes in calculated alveolar ventilation. This computer model-particularly in conjunction with a fixed estimate of anatomical dead space-will, of course, be able to predict changes in arterial blood gases with only limited accuracy.

\section{Results}

The table and figure 2 show the changes observed during SWS and REMS. Significant falls in ventilation and $\mathrm{SaO}_{2}$ occurred. The calculated fall in alveolar ventilation during REM sleep relative to awake periods $(-20 \%)$ is exactly the amount required to produce a fall in $\mathrm{SaO}_{2}$ from $97.3 \%$ to $96.2 \%$ according to the computer model (an approximate fall in $\mathrm{PaO}_{2}$ from $96.5 \mathrm{~mm} \mathrm{Hg}(12.9 \mathrm{kPa})$ to $82.5 \mathrm{~mm} \mathrm{Hg}$ $(11.0 \mathrm{kPa}))$. These falls in ventilation resulted almost entirely from changes in VT and VT/TI and not from changes in timing (f or TI/TTOT). The fractional abdominal contribution to ventilation fell during SW sleep but returned to awake levels during REM sleep. This implies that the actual ribcage and abdominal contributions to ventilation were equally reduced during REM sleep compared and awake periods. The ribcage contribution to ventilation, however, was actually higher during SW sleep than during awake periods even though overall ventila-

Ventilation and oxygen saturation during sleep

\begin{tabular}{|c|c|c|c|}
\hline & Awake & SWS (\% change) & REM (\% change) \\
\hline $\begin{array}{l}\text { Minute ventilation }\left(1 \mathrm{~min}^{-1}\right) \\
\text { Alveolar ventilation }\left(1 \mathrm{~min}^{-1}\right) \\
\text { Frequency/min } \\
\text { Tidal volume (VT) }(\mathrm{ml}) \\
\text { VT/TI }(1 \mathrm{~min}-1) \\
\text { TI/TTOT } \\
\text { Abdominal contribution } \\
\text { Arterial oxygen saturation }(\%)\end{array}$ & $\begin{array}{c}6 \cdot 28 \\
4 \cdot 02 \\
15 \cdot 1 \\
420 \\
17 \cdot 2 \\
0 \cdot 367 \\
0 \cdot 54 \\
97 \cdot 3\end{array}$ & $\begin{array}{c}5 \cdot 67(\downarrow 9 \cdot 7) \\
3 \cdot 38(\downarrow 16) \\
15 \cdot 2(\uparrow 1) \\
373(\downarrow 11) \\
16 \cdot 7(\downarrow 3) \\
0.350(\downarrow 5) \\
0.38(\downarrow 30) \\
96 \cdot 5(\downarrow 1)\end{array}$ & $\begin{array}{c}5 \cdot 44(\downarrow 13 \cdot 0) \\
3 \cdot 21(\downarrow 20) \\
14 \cdot 9(\downarrow 1 \cdot 4) \\
367(\downarrow 13) \\
14 \cdot 7(\downarrow 15) \\
0 \cdot 374(\uparrow 2) \\
0 \cdot 56(\uparrow 4) \\
96 \cdot 2(\downarrow 1)\end{array}$ \\
\hline
\end{tabular}

TI-inspiratory time; TTOT-total respiratory cycle; SWS-slow wave sleep (stages 3 and 4); REM-rapid eye movement sleep. 

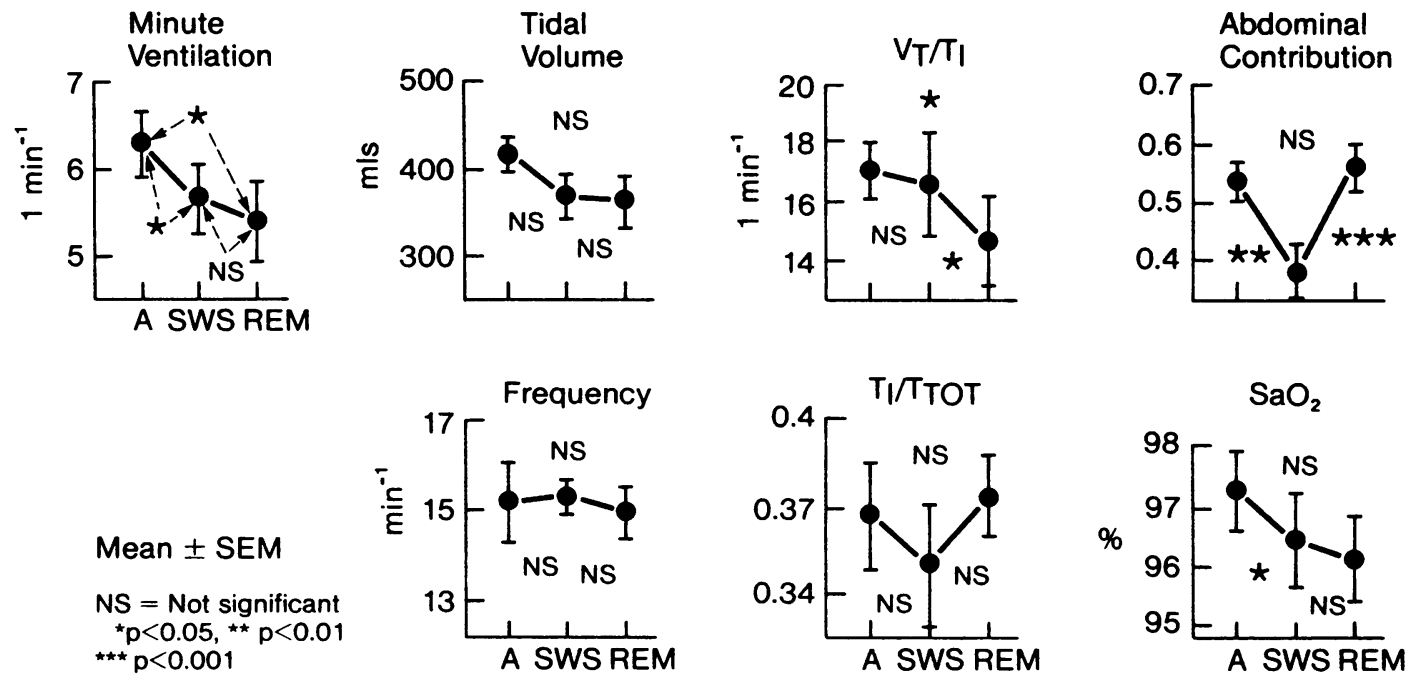

Fig 2 Effect of sleep state on ventilation and its subdivisions and on arterial oxygen saturation. A-awake periods; SWS-slow wave sleep (stages 3 and 4); REM-rapid eye movement sleep.

tion fell.

Snoring had a profound effect the proportions of ribcage and abdominal contributions. In the one subject who snored briefly during an early SW sleep period (not included in the analysis) the abdominal fractional contribution rapidly rose from 0.35 to 0.70 , with a slight increase in minute ventilation that might have been an artefact due to rarefaction of intrathoracic gas with each breath. The changes from one sleep state to another were usually gradual and accompanied by progressive changes in the abdominal contribution (fig 3). These findings show the importance of analysing periods that clearly represent one particular state and are not complicated by snoring.

Figure 4 shows the changes in the coefficient of variation (minute to minute) for all the variables awake-periods and SW and REM sleep. The variability of most of the measurements was less during SW than during REM sleep and awake periods. The variability of $\mathrm{SaO}_{2}$ was highest during $\mathrm{REM}$ sleep, perhaps confirming that ventilation during this state is relatively independent of chemical drives. ${ }^{161728}$

\section{Discussion}

Respiratory inductance plethysmography is more difficult to use accurately than was originally thought. ${ }^{192023}$ Changes in the relationship between body surface motion and the volume of air moving in and out of the lung may be considerable, particularly with the usual changes in posture that occur during sleep. ${ }^{20}$ Simple comparisons made with a spirometer in the same posture before and after sleep do not ensure accuracy in the interim, when both posture and the ribcage-abdominal contributions may alter. Small changes in an initially small VT may produce relatively large changes in alveolar ventilation and thus accurate measurements of ventilation are required to analyse the causes of blood

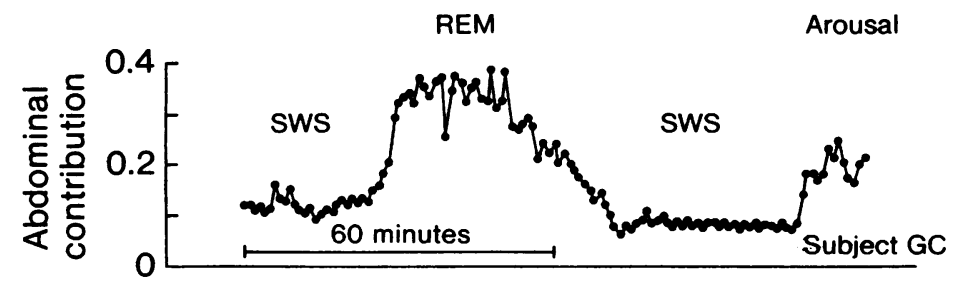

Fig 3 Minute to minute changes in abdominal contribution to ventilation during different sleep states in one subject. Definitions as in figure 2. 

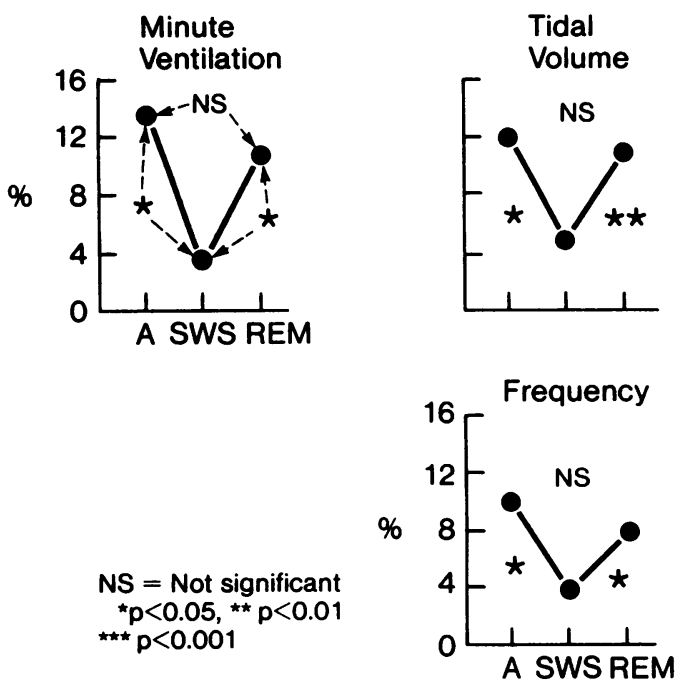

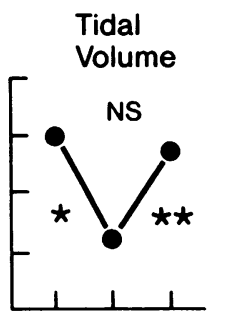

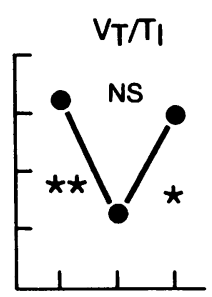

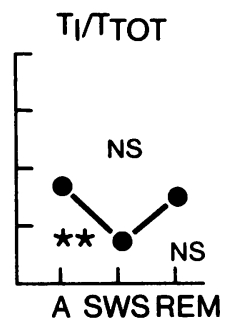

Abdominal Contribution
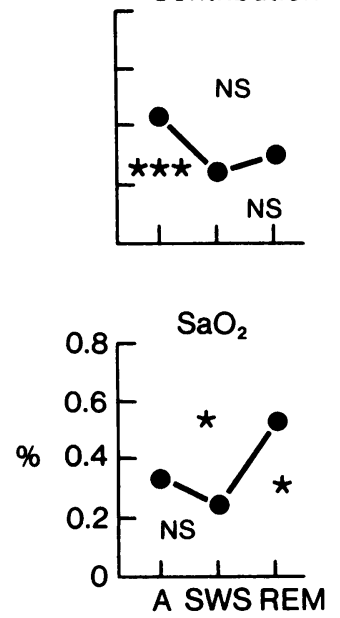

Fig 4 Effect of sleep state on the minute to minute coefficient of variation of ventilation and its subdivisions and on arterial oxygen saturation. Definitions as in figure 2.

gas disturbances. We have shown that multiple linear regression calibration is at least as good as isovolume techniques in deriving $\mathrm{V}-\mathrm{M}$ coefficients ${ }^{23}$ and that deliberate changes in the ribcage and abdominal contributions are necessary to test volume motion coefficients adequately. We believe that, in conjunction with posture restraint and closely adjacent recording periods, these techniques provide the best accuracy in respiratory inductance plethysmography during sleep.

In human subjects abdominal and ribcage movements probably reflect diaphragm and intercostal muscle activities respectively. ${ }^{29}$ The lower ribcage can move either with the bulk of the chest or with the abdomen but the relationship is probably fixed in the one posture and there is evidence to suggest that it is not changed by sleep. ${ }^{30}$ Multiple linear regression calibration weights the two degrees of freedom according to the displaced volume represented by each. If the movement of the lower ribcage results from the action of the diaphragm then the volume of lung gas displaced by this movement will be included with the calculated "abdominal" contribution to ventilation. Isovolume techniques to calibrate the respiratory inductance plethysmograph may well make this relationship different from the relationship found in normal breathing. ${ }^{23}$

We have found significant falls in ventilation during SW and REM sleep and these were adequate to explain the observed reductions in $\mathrm{SaO}_{2}$. The calculated mean fall in $\mathrm{PaO}_{2}$ from awake periods to $\mathrm{SW}$ sleep was $1.4 \mathrm{kPa}(10.5 \mathrm{~mm} \mathrm{Hg})$ and from awake periods to REM sleep $1.9 \mathrm{kPa}(14.0 \mathrm{~mm} \mathrm{Hg})$. These falls are quantitatively similar to those estimated by oximetry in a previous study on patients with chronic airways obstruction. ${ }^{6}$ Although the latter were measured by respiratory inductance plethysmography, with a calibration which would now be regarded as incorrect, the falls in ventilation seen in patients with chronic airways disease during REM sleep were considerably greater and more than enough to account for the degree of extra hypoxaemia. ${ }^{631}$ Reasons for this are being sought, but probably these patients never reach a steady state during REM sleep and periods of increased ventilation save them from even worse hypoxaemia, producing characteristic swings in $\mathrm{SaO}_{2}{ }^{36}$

Results of studies on ventilation during sleep in normal subjects are not entirely similar to ours. The studies of Douglas $e t$ al $^{15}$ were performed at an altitude of $1600 \mathrm{~m}$ with a facemask and the consequent hypoxaemia (end tidal $\mathrm{PO}_{2} 11 \cdot 1 \mathrm{kPa}(84 \mathrm{~mm}$ $\mathrm{Hg})$ ) and $80 \mathrm{ml}$ extra dead space probably account for the higher resting ventilation $\left(7.7 v 6.31 \mathrm{~min}^{-1}\right)$ and the larger fall during REM sleep $(16 \% v 13 \%$, or $39 \% v 20 \%$ if a calculated alveolar ventilation is considered). In some respects these subjects may resemble patients with hypoxic lung disease whose ventilation is being driven by hypoxaemia, and when this drive is reduced by REM sleep ${ }^{1617}$ an exaggerated fall in ventilation might be expected. The increase in respiratory rate during sleep found in Douglas's study was perhaps due to the use of masks which are known to decrease frequency in awake 
subjects, an effect that might disappear with loss of consciousness.

Tabachnik et al, ${ }^{18}$ using respiratory inductance plethysmography, obtained results closer to ours. Their measurements of minute ventilation $\left(1 / \mathrm{min}^{-1}\right)$ were 6.2 (awake), 5.6 (SW sleep) and 5.8 (REM sleep) and of the abdominal contribution 0.60 (awake), 0.34 (SW sleep) and 0.64 (REM sleep). Where differences exist, particularly the larger percentage change in the abdominal contribution and the higher ventilation rate during REM than SW sleep, they would be explicable if the abdominal V-M coefficient had been consistently overestimated. We have calculated from available data ${ }^{19}$ that this would be so if the incorrect two posture calibration technique (erect and supine) is used for a single position supine study. Although it is not stated, this calibration technique is assumed to have been used in Tabachnik's study. This study also found similar changes in $\mathrm{SaO}_{2}$ and in the variability of ventilation with its subdivisions according to sleep state.

While awake, a patient with poor diaphragmatic function can recruit intercostal muscles and accessory muscles of respiration. The $32 \%$ reduction in the ribcage contribution that we have observed during REM sleep could be critical to such patients in making these adaptations with primarily postural muscles no longer available. This change in pattern clearly needs to be confirmed in such patients before being put forward as the explanation for the larger falls in ventilation seen in patients with chronic airways obstruction. ${ }^{631}$ It is worth noting that the changes in derived $\mathrm{PaO}_{2}$ we have seen in the normal subjects are themselves sufficient to produce dramatic falls in $\mathrm{SaO}_{2}$ if the patient's daytime $\mathrm{SaO}_{2}$ is on the steep part of the oxyhaemoglobin dissociation curve $(<85 \%)$.

In conclusion, we have found falls in ventilation and $\mathrm{SaO}_{2}$ during sleep in normal subjects that are sufficient to account for the larger falls in $\mathrm{SaO}_{2}$ seen in patients with hypoxic lung disease. The falls in ventilation were, however, not as great as those seen in some patients with chronic airways obstruction. We have shown changes with sleep state in the ribcage and abdominal contribution to ventilation that could have important consequences when diaphragmatic action is embarrassed.

\section{References}

1 Guilleminault C, Tilkian A, Dement WC. The sleep apnea syndromes. Annu Rev Med 1976;27:465-84.

2 Trask CH, Cree EM. Oximeter studies on patients with chronic obstructive emphysema, awake and during sleep. $N$ Engl J Med 1962;266:639-42.

3 Douglas NJ, Calverley PMA, Leggett RJE, et al. Transient hypoxaemia during sleep in chronic bronchitis and emphysema. Lancet 1979; i:1-4.

4 Flenley DC. Clinical hypoxia: causes, consequences, and correction. Lancet 1978;i:542-6.

5 Block AJ, Boysen PG, Wynne JW. The origins of cor pulmonale. A hypothesis. Chest 1979;75:109.

6 Stradling JR, Lane DJ. Nocturnal hypoxaemia in chronic obstructive pulmonary disease. Clin Sci 1983;64:213-22.

7 Skatrud J, Iber C, McHugh W, Rasmussen H, Nicholas D. Determinants of hypoventilation during wakefulness and sleep in diaphragm paralysis. Am Rev Respir Dis 1979;121:587-93.

8 Tusiewicz K, Moldofsky H, Bryan AC, Bryan MH. Mechanics of the ribcage and diaphragm during sleep. J Appl Physiol 1977;43:600-2.

9 Parmeggiani PL, Sabattini L. Electromyographic aspect of postural respiratory and thermoregulatory mechanisms in sleeping cats. Electroencephalogr Clin Neurophysiol 1972;3:1-3.

10 Tobin MJ, Chadha TS, Jenouri G, Birch SJ, Gazeroglu BS, Sackner MA. Breathing patterns. 2. Diseased subjects. Chest 1983;84:286-94.

11 Askanazi J, Silverberg PA, Foster RJ, Hyman AI, Milic Emili J, Kinney JM. Effects of respiratory apparatus on breathing pattern. J Appl Physiol 1980;48:577-80.

12 Gilbert R, Auchincloss JH, Brodsky J, Boden W. Changes in tidal volume, frequency and ventilation induced by their measurement. J Appl Physiol 1972;33:252-4.

13 Sackner JD, Nixon AJ, Davis B, Atkins N, Sackner MA. Effects of breathing through external dead space on ventilation at rest and during exercise. II. $A m R e v$ Respir Dis 1980;122:933-40.

14 Krieger J, Kurtz D. Effects of pneumotachygraphic recording of breathing on sleep and respiration during sleep. Bull Eur Physiopathol Respir 1983;19:641-4.

15 Douglas NJ, White DP, Pickett CK, Weil J, Zwillich C. Respiration during sleep in normal man. Thorax 1982;37:840-4.

16 Douglas NJ, White DP, Weil JV, et al. Hypoxic ventilatory response decreases during sleep in normal men. Am Rev Respire Dis 1982;125:286-9.

17 Berthon-Jones M, Sullivan CE. Ventilatory and arousal responses to hypoxia in sleeping humans. $\mathrm{Am}$ Rev Respir Dis 1982;125:632-9.

18 Tabachnik E, Muller NL, Bryan AC, Levison $\mathrm{H}$. Changes in ventilation and chest wall mechanics during sleep in normal adolescents. J Appl Physiol 1981; 51:557-64.

19 Zimmerman PV, Connellan SJ, Middleton HC, Tabona MV, Goldman MD, Pride NB. Postural changes in ribcage and abdominal volume-motion coefficients and their effect on the calibration of a respiratory inductance plethysmograph. Am Rev Respir Dis 1983;127:209-14.

20 Stradling JR, Chadwick GA. Inaccuracies in the use of body surface movements to measure ventilation during sleep. Bull Eur Physiopathol Respir 1984;20 (5):12A (abstract).

MA. A transducer for non-invasive monitoring of the respiration. In: Stott F, Raftery EB, Sleight P, Goulding $L$, eds. ISAM Proceedings of the Second Interna- 
tional Symposium on Ambulatory Monitoring. London: Academic Press 1978;119-28.

22 Stradling JR, Nichol CG, Cover D, Davies EE, Hughes JMB, Pride NB. The effects of oral almitrine on pattern of breathing and gas exchange in patients with chronic obstructive pulmonary disease. Clin Sci 1984;66:435-42.

23 Stradling JR, Chadwick GA. Simplifying the use of respiratory inductance plethysmography. Thorax 1984;39:233-4.

24 Rebuck AS, Chapman KR, D'Urzo A. The accuracy and response characteristics of a simplified ear oximeter. Chest 1983;:860-4.

25 Ries AL, Farrow JT, Clausen JL. Accuracy of two oximeters at rest and during exercise in pulmonary patients. Am Rev Respir Dis 1984;129:A79 (abstract).

26 Rechtshaffen A, Kales A. A manual of standardised terminology, techniques and scoring system for sleep stages in human subjects. Washington DC: US Government Printing Office, 1968. (National Institutes of Health Publication 204).

27 West JB. Ventilation-perfusion inequality and overall gas exchange in computer models of the lung. Respir Physiol 1969; 7:88-110.

28 Phillipson EA. Control of breathing during sleep. Am Rev Respir Dis 1978;118:909-39.

29 Gilbert R, Auchincloss JH, Peppi D. Relationship of ribcage and abdominal motion to diaphragm function during quiet breathing. Chest 1981;80:607-12.

30 Mortola JP, Anch AM. Chest wall configuration in supine man: wakefulness and asleep. Respir Physiol 1978;35:201-13.

31 Hudgel DW, Martin RJ, Capehart M, Johnson B, Hill P. Contribution of hypoventilation to sleep oxygen desaturation in chronic obstructive pulmonary disease. J Appl Physiol 1983;55:669-77. 